\title{
Health effects of breast feeding for mothers: a critical review
}

\author{
M. Jane Heinig and Kathryn G. Dewey \\ Department of Nutrition, University of California, Davis, CA 95616, USA.
}

\begin{abstract}
Lactation results in a number of physiological adaptations which exert direct effects on maternal health, some of which may confer both short and long term advantages for breast feeding mothers. Breast feeding in the early postpartum period promotes a more rapid return of the uterus to its prepregnant state through the actions of oxytocin. Breast feeding may also lead to a more rapid return to prepregnancy weight. Among studies that had good data on duration and intensity of lactation, the majority show a significant association between lactation and weight loss. However, there is no evidence that lactation prevents obesity. Lactation also affects glucose and lipid metabolism. The long term effects of these adaptations are unknown but may have implications for preventing subsequent development of diabetes and heart disease. Lactation delays the return of ovulation and significantly reduces fertility during the period of lactational amenorrhoea. This process is linked with feeding patterns and may therefore be affected by practices such as scheduled feedings and the timing of introduction of complementary foods. While the evidence from epidemiologic studies is mixed, several large studies have shown that extended lactation is associated with reduced risk of premenopausal breast, ovarian and endometrial cancers. Although bone mineralization declines during lactation, repletion takes place after weaning. As a result, breast feeding does not appear to cause long term depletion of bone nor does it increase risk of osteoporosis. Many of the physiological effects of lactation are dependent on the stimulation of the hypothalamic-pituitary axis and milk removal and thus may vary with infant feeding practices. Well controlled studies are needed that include detailed information regarding infant feeding practices in addition to the total duration of any breast feeding. Future feeding recommendations should reflect careful consideration of how such practices affect both infant and maternal health.
\end{abstract}

\section{Introduction}

Women often initiate breast feeding because they believe that it confers health benefits on their infants. Many of these benefits have been well documented (Heinig \& Dewey, 1996) and are often included in literature used to promote breast feeding. However, studies examining the health effects of breast feeding for mothers are fewer in number and have often yielded conflicting results.

The decision to breast feed is a personal one and it is not possible to assign women randomly to breast feed or formula feed their infants, nor to predetermine how long women will breast feed them. Thus, scientists must rely on observational epidemiological studies to examine relationships between lactation and subsequent health outcomes for mothers. Interpretation of these studies is complicated by socioeconomic and demographic differences 
often found between groups of women who choose to breast feed and those who choose to formula feed.

Pregnancy and lactation result in a number of physiological adaptations in women which may exert direct effects on maternal health. These changes are largely mediated by the hormonal milieu related to these physiological states and result in general metabolic adaptations as well as structural and functional changes specific to the mammary gland (Glasier \& McNeilly, 1990; Lawrence, 1994). Many of the physiological effects of lactation are dependent on stimulation of the hypothalamic-pituitary axis and milk removal and thus may vary with infant feeding practices.

Methodological issues important in studies examining the effects of breast feeding on infant health were described in a previous review (Heinig \& Dewey, 1996). Four methodological standards described by Bauchner et al. (1986) were used to evaluate many of the studies cited in that review. Briefly, they were (1) avoidance of detection bias, through prospective study design and active surveillance of subjects; (2) adequate control for confounding variables; (3) clearly defined outcome events; and (4) a clear definition of 'breast feeding'.

These standards are equally important in the evaluation of studies examining the health effects of breast feeding for mothers. While results from prospective studies are less subject to detection bias, the majority of the research detailed in this report is retrospective because these studies are more feasible when examining long term effects of breast feeding. Many of the studies, particularly those examining risk factors for disease in the postmenopausal period, rely on maternal recall of lactation behaviours that took place many decades before the measurements. Control for potential confounding variables is extremely important when examining long term health effects of breast feeding, given that health status is known to be affected by many factors. For example, age at first birth and family history of breast cancer are important risk factors for breast cancer (Mansfield, 1993). Any studies examining the relationship between lactation and breast cancer should include these variables. A clear definition of outcomes is important for comparisons across studies. Differences in assessment methods may result in differences in results. For example, the site used to measure bone density may affect results because certain types of bone are more sensitive to mobilization (Kent et al. 1990).

Although the majority of women breast fed their infants in the early part of this century, aggressive promotion of artificial feeding methods resulted in a worldwide drop in breast feeding rates and duration from the 1950 s through the 1970s. Furthermore, medical recommendations surrounding infant feeding have changed a number of times over the last $\mathbf{5 0}$ years, resulting in changes in infant feeding practices. For example, scheduled feedings and introduction of solid foods in the first 2 months of life are less common now than they were only 20 or 30 years ago. Researchers examining the long term effects of breast feeding on maternal health often do not account for differences in feeding practices. In many of the studies, women who breast fed at any time were compared with those who never breast fed. Therefore, 'breast feeding' groups could include women who breast fed only once or twice in the hospital as well as those who breast fed exclusively for 4-6 months and partly for one or two years.

This review will focus primarily on studies which evaluate claims of health advantages for breast feeding mothers and will not include studies of breast feeding during maternal illness (e.g. insulin dependent diabetes mellitus) nor studies that examine the relationship between lactation and maternal nutritional status or immune function. These latter topics have been reviewed by others (Institute of Medicine, 1991; Lawrence, 1994). The studies selected for this review meet at least 3 of the 4 criteria listed by Bauchner et al. (1986). Greater attention is given to studies that provide information on the duration and/or exclusivity of breast feeding in the definition of feeding practices. 


\section{Physiology of lactation}

Detailed descriptions of the physiological changes that occur during lactation have been published by others (Mepham, 1987; Lawrence, 1994) and are beyond the scope of this report. However, we will summarize some of them here because many of the health effects of breast feeding for mothers are directly influenced by these changes.

\section{Breast development and lactogenesis}

Breast development is influenced by a number of hormones including oestrogens, progesterone, prolactin (PRL) and human placental lactogen. During the first half of pregnancy, circulating hormones cause primitive lobular structures to increase in size and complexity. Luteal and placental hormones induce increases in ductular sprouting, branching and lobular formation. Prolactin acts to complete the development of highly differentiated secretory alveolar structures at the ends of the ducts (Lawrence, 1994).

During pregnancy, circulating progesterone and human placental lactogen inhibit the milkproducing actions of prolactin. After the placenta is delivered, in the early postpartum period, levels of progesterone and human placental lactogen drop rapidly while PRL remains high. PRL has many actions during both lactogenesis and established lactation, including stimulation of transcription of casein messenger RNA and synthesis of lactalbumin. PRL also increases lipoprotein lipase (EC 3.1.1.34) activity in the mammary gland. The actions of PRL are interrelated with those of a variety of pituitary, ovarian, thyroid, adrenal, and pancreatic hormones. Copious milk production normally occurs at $2-4 \mathrm{~d}$ post partum and is not dependent on infant suckling. However, maintenance of milk production is dependent on infant suckling and milk removal.

\section{Maintenance of milk production}

Infant suckling stimulates the release of prolactin, which in turn stimulates milk production and secretion. Prolactin also acts to increase fat synthesis in the mammary tissue and to increase fat mobilization in other parts of the body. Prolactin levels can vary greatly from woman to woman, even among women producing similar amounts of milk.

When suckling occurs, another hormone, oxytocin, is released into the circulation and causes the ejection of milk from the alveoli into the ducts and lactiferous sinuses. Without the 'milk-ejection reflex', sufficient emptying of the breast does not occur and lactation eventually fails. Oxytocin also speeds the involution of the uterus (Institute of Medicine, 1991).

Sufficient emptying of the breast is believed to be essential for the maintenance of lactation. Lack of emptying may induce breast engorgement, resulting in increased pressure in and distention of the mammary gland. Studies in animals have shown that increased pressure in the alveoli caused by pooling of milk will result in a rapid decrease in milk secretion (Neville \& Neifert, 1983). In addition, animal studies have indicated that milk synthesis may be closely controlled within each mammary gland. Wilde and coworkers (Wilde et al. 1988) found a constituent of milk whey protein that inhibits milk secretion within the mammary gland of goats. If milk remains in the breast after milking, the concentration of this protein inhibitor is believed to increase, resulting in a negative feedback inhibition of further milk production. If the milk is removed, the inhibitor is also removed and milk production is not inhibited. 
Evidence from human studies also supports this mechanism. Daly \& Hartmann (1995) have shown that the rate of milk synthesis in women is highly related to milk removal and is controlled independently in each breast. This autocrine control of lactation may explain why milk volumes vary widely between breasts in some women.

Though the mechanism is not completely understood, infant suckling also interrupts the pulsatile secretion of gonadotrophin releasing hormone ( $\mathrm{GnRH})$ from the hypothalamus, which in turn inhibits the pulsatile release of luteinizing hormone from the pituitary gland. Luteinizing hormone is required for maturation of the ovarian follicle. Insufficient pulsatile luteinizing hormone therefore results in the temporary cessation of ovulation and the reduction of circulating oestrogens and progesterone. As suckling diminishes, pulsatile release of these hormones normalizes and ovulation returns. Prolactin does not appear to play a direct role in this process (McNeilly et al. 1994). Thus, suckling frequency, intensity, and timing influence ovulatory status.

\section{Breast changes during weaning and menopause}

When infant suckling greatly diminishes or ceases altogether, the lack of stimulation to the breast reduces prolactin release. Increased pressure in the alveoli and the presence of inhibitors result in decreased milk secretion. The alveoli become distended and eventually the secretion remaining in the ducts is reabsorbed. Over time, the alveoli collapse and involute. The functional tissue is slowly replaced by adipose and connective tissue (Kuhns \& Ackermann, 1995).

After menopause, the lack of circulating oestrogens results in further involution of the gland. The alveoli and intralobular ducts disappear. The absolute number of lobular units also declines and the connective tissue becomes more collagenized and less cellular. The timing and degree of these changes vary from woman to woman, with some women retaining premenopausal-like lobular structures well into their 70s (Kuhns \& Ackermann, 1995).

\section{Epidemiological studies}

\section{Recovery from childbirth}

Breast feeding immediately after birth promotes maternal recovery from childbirth. Infant suckling stimulates the release of the hormone oxytocin into the mother's bloodstream. Oxytocin stimulates uterine contractions, which in turn help to expel the placenta and minimize maternal blood loss. Continued breast feeding promotes uterine involution to its nonpregnant state (Institute of Medicine, 1991; Riordan, 1993).

\section{Maternal postpartum weight loss}

Repeated pregnancy without lactation has been shown to promote obesity in rats (Jen $e t$ al. 1988). However, there are conflicting results as to whether breast feeding women lose weight more rapidly than non-breast feeding women in the postpartum period (Table 1). These inconsistent results have been attributed to (a) differences in the definition of breast feeding and in the timing of baseline measurements; (b) differences in the outcome variables examined; (c) 
Health effects of breast feeding for mothers: a critical review

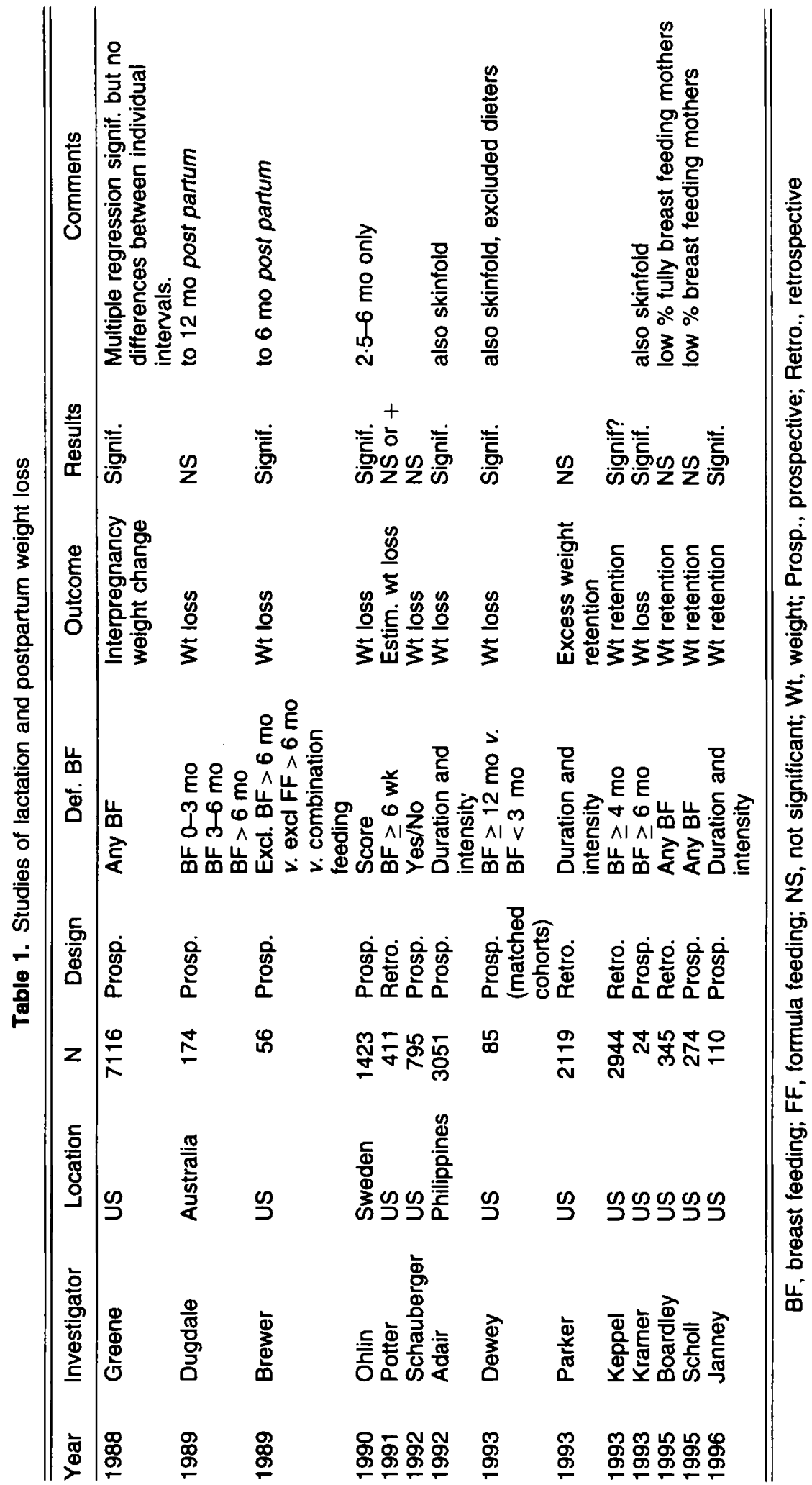


lack of sufficient numbers of women who breast feed longer than a few months; and (d) inclusion of women on weight loss diets (Dewey et al. 1993). The last issue is important because breast feeding women are less likely than non-breast feeding women to restrict their energy intake, owing to concern that dieting will affect their milk production.

Table 1 shows that, of the 14 studies listed, six reported no relationship between infant feeding and weight loss (Dugdale \& Eaton-Evans, 1989; Potter et al. 1991; Schauberger et al. 1992; Parker, 1993; Boardley et al. 1995; Scholl et al. 1995). Three of these studies defined breast feeding as 'any' $v$. 'none'. Another one (Potter et al. 1991) included in the breast feeding group any women who breast fed for at least 6 weeks post partum, which may not have been long enough to result in weight loss.

Of the 10 studies which defined breast feeding as a duration greater than 3 months or included information on duration and intensity of breast feeding, 8 found an association between weight loss and lactation (Greene et al. 1988; Brewer et al. 1989; Öhlin \& Rössner, 1990; Adair \& Popkin, 1992; Keppel \& Taffel, 1993; Kramer et al. 1993; Dewey et al. 1993; Janney et al. 1996) and 2 did not (Dugdale \& Eaton-Evans, 1989; Parker, 1993). The study of Dugdale \& Eaton-Evans (1989) showed that weight loss in the first 11 months post partum did not differ among groups who breast fed their infants for either $0-3,3-6$, or 6-9 months. However, nonlactating women were included in the same group as women who breast fed for up to 3 months. In the study by Parker et al. (Parker, 1993), there was no association between lactation and retention of excess weight (more than 20 pounds) at 10-18 months after delivery among women participating in the National Maternal and Infant Health Survey. Given the nature of this outcome variable, it may have been more difficult to detect an impact of breast feeding.

Only one study excluded women who were actively dieting to lose weight (Dewey et al. 1993). In that study, weight loss was compared between women who breast fed their infants for at least 12 months and women who weaned their infants to formula by 3 months. The breast feeding mothers lost an average of 4.5 pounds more from 1 to 12 months than the formula feeding mothers. On average, the breast feeding mothers had returned to their prepregnancy weight by 12 months, whereas the formula feeding mothers were still 4-5 pounds above their prepregnancy weight at 24 months post partum. Among breast feeding mothers, the weight lost during lactation was not regained in the second year post partum.

Although there are still very few studies in humans, there is no evidence that lactation prevents subsequent obesity (Institute of Medicine, 1991; Bjorkelund et al. 1996; Rush et al. 1996). Furthermore, it is important to note that weight loss attributable to lactation is not considered to be an advantage in all societies, and that among disadvantaged populations extended lactation may contribute to depletion of maternal energy reserves (Adair \& Popkin, 1992). It is also worth mentioning that not every woman loses weight during lactation. In one study (Manning-Dalton \& Allen, 1983), 22\% of the women gained weight while breast feeding during the first 6 months post partum. Although the energy needs of lactating women are greater than those of nonlactating women (Institute of Medicine, 1991), increased appetite while breast feeding may compensate for this. In rats, prolactin has been shown to stimulate food intake (Moore et al. 1986). If this is also true for humans, prolactin may be responsible for increased appetite in early lactation when concentrations are highest (Howie \& McNeilly, 1982; Gross \& Eastman, 1985). It would follow that nonfluid weight loss would not differ between lactating and nonlactating women in the early postpartum period and that a short duration of breast feeding is not likely to affect weight loss post partum. Prolactin levels normally decrease during lactation even if exclusive breast feeding continues. If this results in decreased appetite, it may explain why breast feeding beyond the first 6 months has been 
associated with more rapid weight loss. Very few studies have compared weight loss between lactating and nonlactating women beyond six months post partum. Further research is needed to understand the impact of lactation on maternal weight and body composition throughout the first year post partum.

\section{Metabolism of lipids and glucose}

Lactating mothers secrete large amounts of cholesterol into their milk, averaging 15-20 mg cholesterol/100 $\mathrm{ml}$ of milk among exclusively breast feeding women (Kallio et al. 1989). This results in an output of $\sim 150 \mathrm{mg} / \mathrm{d}$, which roughly equals the amount of cholesterol lost by malabsorption induced by cholesterol lowering medications (Kallio et al. 1992). During pregnancy, serum cholesterol and triglyceride concentrations increase over prepregnancy levels (Knopp et al. 1982a,b). After delivery, triglyceride concentrations decline rapidly to the normal range for nonpregnant women whereas total cholesterol and low-density lipoprotein cholesterol decline more slowly, remaining above prepregnancy levels for at least 6 weeks post partum in both lactating and nonlactating women (Knopp et al. 1985a,b; Jimenez et al. 1988). Among lactating women, high-density lipoprotein cholesterol levels remain high after delivery (Knopp et al. 1982, 1985b; Kallio et al. 1992). Prolactin activates an enzyme in the mammary gland that increases the clearance of plasma triglycerides and increases the concentration of highdensity lipoprotein (Kallio et al. 1992). In a study of cholesterol metabolism in women who exclusively breast fed their infants for up to 12 months (Kallio et al. 1992), total cholesterol, low-density lipoprotein, and triglycerides declined to levels significantly lower than nonpregnant nonlactating values during lactation and then returned to their normal levels after lactation ceased. During periods of lactation, maternal physiological changes promote secretion of cholesterol into milk and may improve lipid profiles with respect to risk for cardiovascular disease. While these changes appear to be limited to the duration of lactation, it is possible that repeated extended lactations may retard the development of atherosclerotic damage. Further associations between extended lactation and the development of heart disease remain to be explored.

Kjos et al. (1993) examined the effect of lactation on lipid and carbohydrate metabolism in women with recent gestational diabetes. At 6 weeks post partum, lactating women had lower fasting glucose levels and improved glucose metabolism as compared to nonlactating women after adjusting for age, fatness and mean arterial blood pressure. More of the nonlactating women had required insulin during pregnancy, but differences between groups remained significant after adjustment for insulin use. Furthermore, results were similar when separate analyses were performed within subgroups of women who had used diet to control their gestational diabetes $v$. those who had required insulin. Lenz et al. (1981) also found significantly lower fasting glucose and insulin levels among normal lactating $v$. nonlactating women at 8 weeks post partum.

\section{Suppression of fertility}

Breast feeding women are known to have a more prolonged period of postpartum anovulation than those who formula feed their infants. Increased spacing between births is known to improve the health of both childbearing women and their infants. Consequently, breast feeding promotion is part of family planning and maternal and child health programmes in many 
different countries around the world (Wang \& Fraser, 1994). However, in western societies breast feeding is not considered to be a reliable method of contraception after the first 2-3 months (Perez, 1981). Although the physiological mechanisms underlying the contraceptive effect of breast feeding are not completely understood, infant feeding practices play a crucial role (McNeilly et al. 1994).

Among nonlactating women, ovulation returns by $40-50 \mathrm{~d}$ post partum and menstruation returns on average by 55-60 d post partum. Return of menstruation among breast feeding women varies greatly and is influenced by infant feeding patterns (Wang \& Fraser, 1994). Frequency, intensity and timing of feeds influence endocrine responses that modulate ovulatory status (Campbell \& Gray, 1993; McNeilly et al. 1994).

Supplementary foods and fluids given to the infant may influence these factors (Howie et al. 1981). In a study examining the influence of supplementation on return to ovulation (Howie \& McNeilly, 1982), Howie et al. identified characteristics of women who ovulated while breast feeding. By the time of their first ovulation, these women had introduced two or more supplementary feedings per day, eliminated night feeds and reduced sucking frequency to less than $60 \mathrm{~min} / \mathrm{d}$. However, it is possible that women who supplement sooner may be those who initially have lower milk volumes due to reduced nursing duration or frequency, and thus would be predisposed to a shorter duration of lactational amenorrhoea. In a longitudinal intervention study, Dewey et al. (1977) randomly assigned Honduran women who had exclusively breast fed for 4 months to one of three groups: continued full breast feeding until 6 months post partum, introduction of complementary foods at 4 months with ad lib. breast feeding from 4 to 6 months, or introduction of complementary foods at 4 months with maintenance of baseline breast feeding frequency from 4 to 6 months. In this study, the introduction of solid foods at 4 months reduced the likelihood of amenorrhoea at 6 months post partum, but not thereafter. This effect was not seen in the group that maintained breast feeding frequency. Therefore, the effect of complementary foods on duration of lactational amenorrhoea appears to be mediated through changes in nursing frequency.

Early postpartum cycles tend to be anovulatory, especially among women who are still breast feeding (Perez et al. 1972; Diaz et al. 1992; McNeilly et al. 1994). However, the longer the period of lactational amenorrhoea, the more likely that ovulation will precede the first cycle (Perez et al. 1972; Short et al. 1991).

In 1988, researchers from around the world gathered in Italy to discuss their research on the effect of breast feeding on fertility. Among 13 studies presented by the researchers, the highest pregnancy rate reported in fully breast feeding, amenorrhoeic women during the first 6 months post partum was less than $2 \%$ (Kennedy et al. 1989). In their consensus statement, the international group of scientists stated that "Breast feeding provides $98 \%$ protection from pregnancy during the first six months postpartum if the mother is fully or nearly fully breast feeding and has not experienced vaginal bleeding after the 56th day postpartum. Additional contraception is required in lactating women who are only partially breast feeding, who have started menstruating, or who have been breast feeding for more than six months" (Kennedy et al. 1989). Further research has shown that lactational amenorrhoea can provide reasonable protection against conception for up to 12 months. However, once menstruation resumes, other forms of contraception are necessary (Short $e t$ al. 1991). Thus, infant feeding practices have an important influence on the effectiveness of breast feeding as a form of contraception. In western societies, the frequency of breast feeding is often restricted to 6 episodes/d and supplementary foods or milks are commonly given in the first few months. Additionally, many mothers do not offer night feeds after the first few weeks (Wang \& Fraser, 1994). These feeding practices contribute to early return to menstruation and ovulation (McNeilly et al. 1994). 


\section{Cancer risk}

\section{Breast cancer}

In 1985, Byers et al. found a negative association between lactation and breast cancer risk among white premenopausal women even after controlling for confounding factors including age, parity, age at menarche, age at first pregnancy, and years of education. As part of the discussion of that study, Byers and colleagues presented the results from 17 studies published between 1966 and 1983 examining the relationship between lactation and risk of breast cancer. Eight of the 12 studies that presented age-specific data showed a lower relative risk estimate among younger women ( $<50$ years of age) who had ever breast fed their children as compared to those who had not. The researchers pointed out the need for well controlled studies that included details regarding the duration of lactation.

In the last 12 years, more than 20 studies (Table 2) have examined the relationships between various reproductive factors, including breast feeding, and subsequent risk of breast cancer in parous women. Breast cancer has been consistently associated with several maternal factors: age at first pregnancy, parity, family history of breast cancer, and age at menarche and menopause. In several studies, a protective effect of breast feeding was also found, particularly among premenopausal women (McTiernan \& Thomas, 1986; Tao et al. 1988; Yuan et al. 1988; Layde et al. 1989; Yoo et al. 1992; Chilvers, 1993; Newcomb et al. 1994; Romieu et al. 1996). However, little or no association between breast cancer and lactation history was found in other studies, including several retrospective case-control studies (Rosero-Bixby et al. 1987; Siskind et al. 1989; Adami et al. 1990; Laing et al. 1993; Thomas \& Noonan, 1993; Yang et al. 1993; Katsouyanni et al. 1996; Negri et al. 1996; Wu et al. 1996), a prospective study involving more than 50000 women in Norway (Kvale \& Heuch, 1987), a retrospective cohort study of US nurses (London et al. 1990), and a follow-up prospective study in a subsample of the latter cohort (Michels et al. 1996). Among the US nurses, $60 \%$ had a lifetime duration of breast feeding of 3 months or less (Michels et al. 1996). Typically, appreciable reduction in cancer risk is seen only when breast feeding is prolonged. The cumulative duration of breast feeding required for reduction in cancer risk ranged from 4 months to 8 years among studies reviewed by Newcomb et al. (1994). Among 10 studies that included women with extended lactation (greater than 1 year lifetime duration) and in which data were analysed separately for pre- and postmenopausal women, 6 found a reduction in risk of breast cancer associated with lactation (McTieman \& Thomas, 1986; Yoo et al. 1992; Chilvers, 1993; Yang et al. 1993; Newcomb et al. 1994; Romieu et al. 1996) and 4 did not (Siskind et al. 1989; Thomas \& Noonan, 1993; Katsouyanni et al. 1996; Negri et al. 1996). Breast feeding was not associated with a higher risk of breast cancer in any study among parous women.

Among the 10 studies listed above, classification of lactation duration varied considerably, making comparisons across studies difficult. McTiernan \& Thomas (1986) reported that premenopausal women who had ever lactated had less than one-half the risk of developing breast cancer as those in the nonlactating control group. The lowest relative risk was among premenopausal women with more than 13 months of cumulative breast feeding experience. The protective effect of breast feeding was unchanged after controlling for maternal age, parity, and age at first pregnancy. Controlling for these same variables, Yoo et al. (1992) found the lowest risk to be among premenopausal women who had lactated for 7-9 months.

Among women younger than 36 years, researchers in the UK found a lower risk of breast cancer associated with the number of children breast fed for at least 3 months (Chilvers, 1993). There was no further decrease in risk associated with breast feeding beyond 3 months per child. 


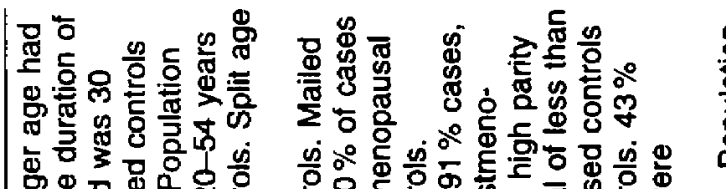

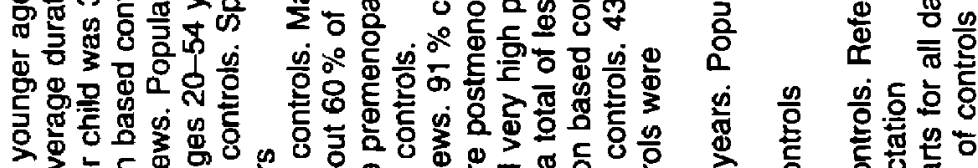

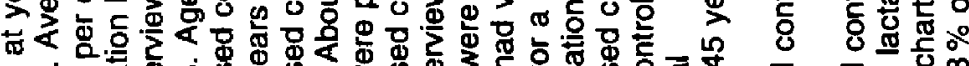

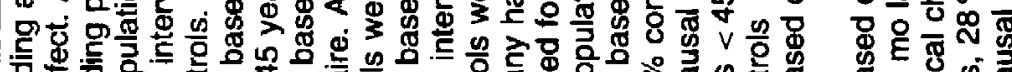

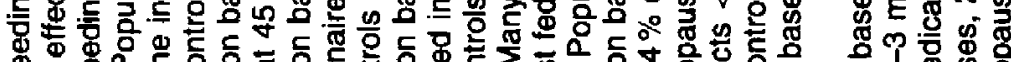
Ф

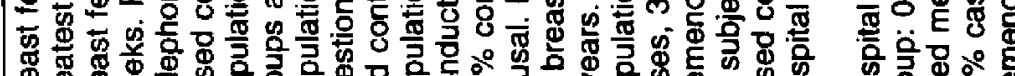

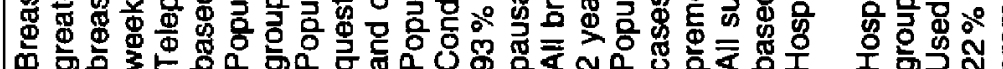

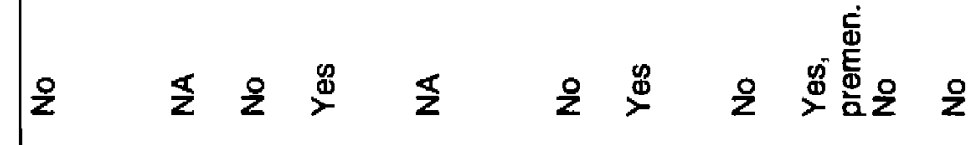

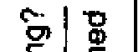
능

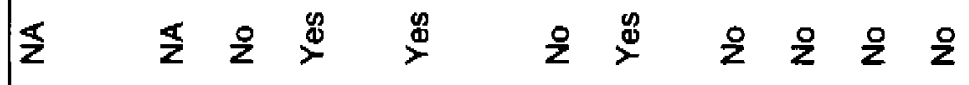

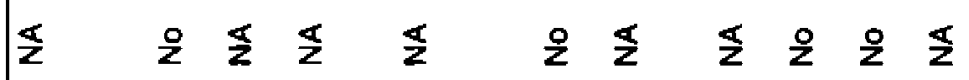

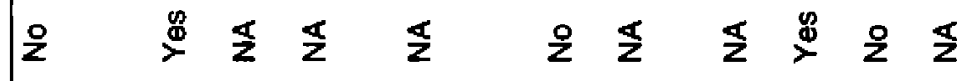

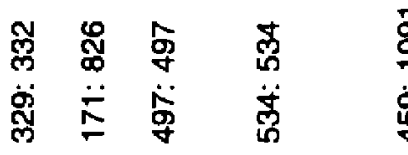

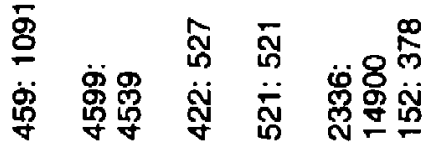




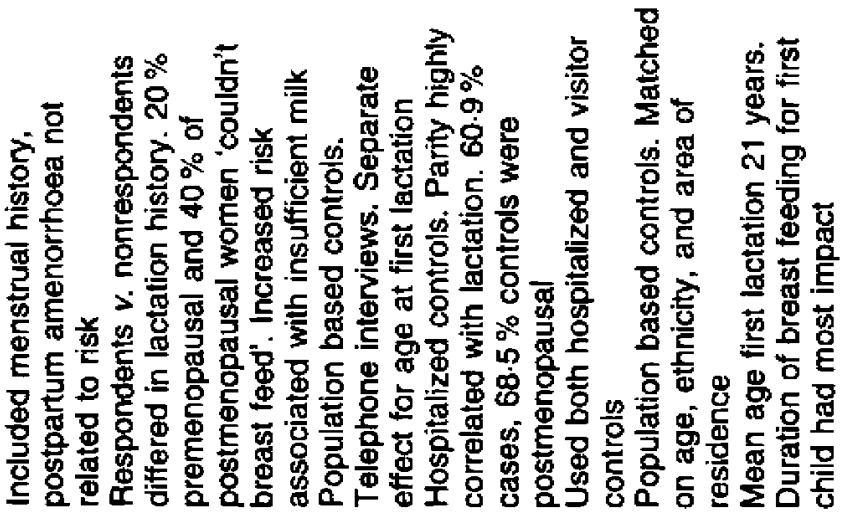

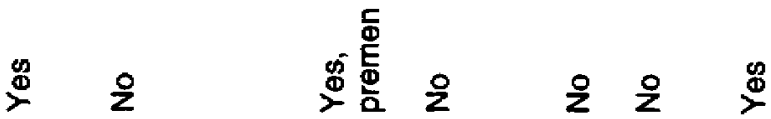

$\frac{1}{z} \quad \stackrel{0}{z} \quad \stackrel{0}{2} \stackrel{g}{2}$

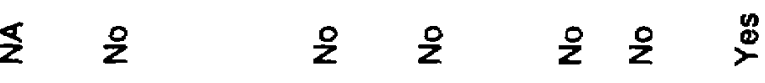

$\stackrel{8}{\circ} \stackrel{0}{2}$

$\stackrel{\infty}{>} \stackrel{\circ}{2} \stackrel{\circ}{\llcorner}$

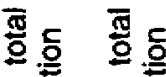

定要

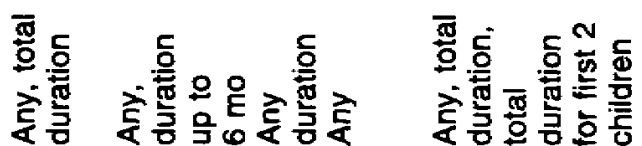

总

罢哭

宮

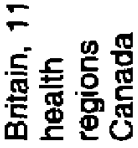

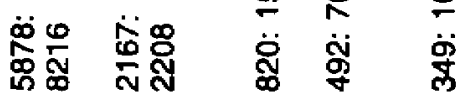

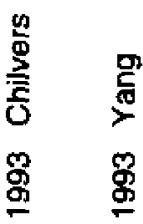

응 응

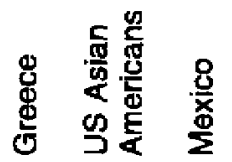

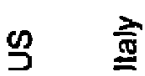

声 息

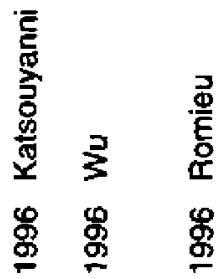


Yang and coworkers (1993) reported similar results from a case-control study conducted in Canada. While decreased risk was found among women who breast fed for at least 2 months, no additional reduction in risk was found among women with a lifetime breast feeding duration from 2 to more than 25 months. Romieu et al. (1996) found decreasing risk with increasing duration of breast feeding among both pre- and postmenopausal women in Mexico. Duration of the first lactation was related to the greatest decrease in risk while subsequent periods of lactation were found to reduce risk only among postmenopausal women.

In a multicentre study involving more than 14000 pre- and post-menopausal women, lactation history was associated with a reduction in the risk of breast cancer only among premenopausal women (Newcombe et al. 1994). Cancer risk was $22 \%$ lower among premenopausal women who had ever breast fed than among those who had not. Total duration of lactation was also associated with a reduction in the risk of breast cancer among the premenopausal women. For premenopausal women with a cumulative total of more than 24 months of lactation, the risk of breast cancer was $28 \%$ lower than that for women who had never breast fed. Age of the mother when she first breast fed also independently influenced her risk of cancer. The lowest risk for premenopausal breast cancer was calculated to be among women who breast fed for at least 6 months and had been 20 years old or younger when they initiated lactation for the first time. The authors of the study estimated that, if all women with children breast fed for a total of 4-12 months, breast cancer among premenopausal women could be reduced by $11 \%$. In addition, they suggested that if women with children breast fed for a lifetime total of 24 months or longer, the incidence of breast cancer might be reduced by almost $25 \%$.

Thomas \& Noonan (1993) assessed the relationship between breast feeding and risk of breast cancer among more than 17000 women from 10 different countries. While the relative risks for groups of women who had lactated for more than 12 months $v$. those who had breast fed for less than three months were consistently less than unity, the calculated $95 \%$ confidence interval estimates included one. This was true among both pre- and postmenopausal women. No trend of decreasing risk was associated with increasing duration of lactation. Similarly, Katsouyanni et al. (1996) found an odds ratio of 0.50 among Greek premenopausal women who had breast fed for at least 12 months. However, the $95 \%$ confidence interval ranged from 0.23 to 1.41 . There was no relationship between breast feeding and risk of breast cancer among postmenopausal women in that study. Negri et al. (1996) found no association between breast feeding and risk of breast cancer among Italian women. In that study, lactation greater than 6 months was coded as 6 , potentially underestimating lifetime breast feeding duration among women with prolonged lactation.

Siskind et al. (1989) found a significant nonlinear relationship between lactation and the risk of breast cancer among Australian women. A slightly higher odds ratio was calculated for lactation of less than one month, a lower odds ratio for lactation of 1-3 months and, a slightly higher odds ratio in women breast feeding longer than 9 months as compared with parous women with no lactation. This was true for both pre- and postmenopausal women.

Discrepancies among studies may be related to many factors. Underlying differences in study design and methods, breast feeding practices and nonreproductive variables such as diet and family history may contribute to conflicting results. Furthermore, the biological mechanisms underlying the association between breast feeding and cancer have not been elucidated. Prolactin apparently does not play a role in the association between breast feeding and breast cancer (Wang et al. 1992). The link may be related to reduced exposure of the breast to oestrogen and other steroids during the reproductive period (Henderson et al. 1982; Petrakis et al. 1987; Institute of Medicine, 1991; Shi et al. 1994). Exposure to these hormones results in 
repetitive cellular proliferation which is associated with higher risk of neoplastic transformation (Spicer \& Pike, 1994). There is evidence from animal studies that mammary cells in young animals may be particularly susceptible to carcinogens, which may explain why age at first pregnancy is related to risk for breast cancer (Brinton et al. 1983). Lactation may also result in the removal of potential carcinogenic compounds from the breast ducts (Josephy, 1996). In addition, physical changes in the breast during lactation may influence cancer risk (Petrakis $e t$ al. 1987; Russo \& Russo, 1995). In a study among women who breast fed with only one breast (Ing et al. 1977), researchers found a four-fold increase in risk of cancer in the unsuckled breast after menopause.

Russo \& Russo (1995) described increased numbers of highly differentiated lobules in the breast tissue of parous women as compared to that of nulliparous women. These lobular structures, identified as Types 3 and 4 , predominate during pregnancy and lactation. These highly differentiated structures are more resistant to neoplastic transformation in comparison with the relatively undifferentiated Type 1 lobules which predominate in the breast tissue of nulliparous women. It is unknown how prolonged lactation in women may affect the proportions of these structures. However, Russo and colleagues found no permanent morphological differences between rats that had lactated and parous rats that had not lactated (Russo et al. 1982). During the postmenopausal period, many of the Type 3 and 4 lobules revert to Type 1 lobules. There is evidence to suggest that these structures remain more resistant to neoplastic conversion after menopause as compared to Type 1 cells found in the tissues of nulliparous women (Russo \& Russo, 1995).

To summarize, it is known that pregnancy and lactation cause significant changes in concentrations of circulating hormones which result in systemic metabolic effects as well as structural changes in the breast. In theory, these changes may reduce the risk for spontaneous neoplastic transformation in breast tissue. However, evidence from epidemiological studies is mixed. This could be due in part to the fact that few studies have accounted for differences in feeding patterns among breast feeding women, which are known to affect circulating hormone levels. It is also possible that breast feeding protects against only certain types of malignancies. Tumours differ widely in their site of initiation and sensitivity to hormonal influences (Mansfield, 1993), yet most case-control studies do not consider the type of tumour as an outcome. Finally, the evidence suggests that the reduction of cancer risk associated with lactation is found primarily among premenopausal women. Risk factors differ for pre- $v$. postmenopausal breast cancer (Kampert et al. 1988). Future studies are needed which carefully examine the relationships among feeding practices, tumour type and menopausal status in women with breast cancer.

\section{Ovarian and endometrial cancer}

Relatively few studies have examined the effect of lactation on the risk of ovarian cancer. In a meta-analysis of 12 case-control studies conducted in the US, breast feeding for 6 months or longer was associated with a reduced risk of ovarian cancer among parous white (Whittemore et al. 1992) and black (John et al. 1993) women. In a multinational study (Rosenblatt et al. 1993), a 20-25\% decrease in risk of ovarian cancer was observed in women who lactated for at least 2 months per pregnancy, compared to those who had not. Little or no further decrease in risk was seen with increasing duration of lactation. Risch et al. (1983) and Gwinn et al. (1990) reported a decreased risk of epithelial ovarian cancer with increasing length of lactation. These authors hypothesized that lactation may exert a protective effect via inhibition of ovulation. However, they also reported that the reduced cancer risk associated with lactation was not fully explained by lactational anovulation. In contrast, several studies have identified no reduction in 
ovarian cancer risk associated with lactation (West, 1966; Hildreth et al. 1981; Wynder et al. 1981; Cramer et al. 1983; Hartge et al. 1989).

It has been hypothesized that ovulation itself or the circulating levels of pituitary gonadotrophins may increase the risk of ovarian malignancy, and that pregnancies, oral contraceptives and lactation may be protective by limiting the release of these hormones and suppressing ovulation (Whittemore, 1994). However, the lack of increased risk associated with oestrogen replacement therapy suggests that risk factors for ovarian cancer may differ between pre- and postmenopausal women.

The risk of endometrial cancer is believed to increase with exposure to circulating oestrogens unopposed by progesterone (Voigt \& Weiss, 1989). During breast feeding, circulating oestrogens are reduced more than is progesterone (Baird et al. 1979). Therefore, breast feeding may be protective against endometrial cancer.

Two multicentre case-control studies provide conflicting evidence regarding the relationship between lactation and endometrial cancer. After controlling for parity, Brinton and coworkers (1992) reported no difference in risk for endometrial cancer between women who had ever breast fed and those who had never breast fed among 700 women from five areas in the US. In a multicentre case-control study conducted in 6 different countries, Rosenblatt \& Thomas (1995) found a significant decreasing trend in risk of endometrial cancer with increasing cumulative duration of lactation, and with months of breast feeding per pregnancy. However, odds ratios for specific lactation intervals were significant only among women who breast fed for a total of more than $\mathbf{7 2}$ months. In that study, data were collected regarding total breast feeding duration, months of breast feeding per pregnancy, years since the mother's first and last lactation and age at first lactation. The reduction in risk was greatest in women who had recently lactated and there was no protective effect in women over 55 years of age, among whom the disease is most common.

If the association between lactation and reduced risk of ovarian and endometrial cancers is related to the duration of postpartum anovulation, infant feeding practices may also be related to risk. There is also evidence to suggest that the effect of lactation may be limited to the premenopausal period. Future studies should account for differences in feeding practices among breast feeding women and analyse risk for pre- and postmenopausal women separately.

\section{Changes in bone density}

Osteoporosis is a chronic condition affecting millions of people in many countries, predominantly women. The condition, which occurs as a consequence of progressive loss of bone mass, is characterized by fractures following even minimal trauma (Mehta, 1993). While bone loss occurs with age in both men and women, the rate at which bone density declines may be affected by many factors. Cross-sectional studies conducted in a number of populations indicate that there may be racial as well as regional differences in susceptibility to osteoporosis. Studies conducted in the US indicate that black Americans have higher bone mass, thicker bone cortex, greater vertebral bone density and fewer vertebral fractures than white Americans (Cohn et al. 1977). Asian Americans appear to have less cortical bone than white Americans (Yano et al. 1984). Incidence of osteoporosis and hip fracture vary widely from country to country (Mehta, 1993). However, the reasons for geographical variations in risk are unknown. Differences in diet, degree of physical activity and exposure to sunlight have been suggested as factors contributing to these differences in risk (Mehta, 1993). It is known that women lose 
bone faster with age and therefore have a higher lifetime risk for osteoporosis and fractures than men (Melton \& Riggs, 1983).

Fully lactating women secrete $240-320 \mathrm{mg}$ of calcium in breast milk daily. Over 6 months of lactation, the total need for calcium is approximately $50 \mathrm{~g}$ or about $5 \%$ of total body calcium (King et al. 1992). In nonpregnant, nonlactating women, parathyroid hormone (PTH) is released in response to the need for calcium, which in turn increases the renal hydroxylation of $25(\mathrm{OH})$ vitamin $\mathrm{D}$ and thus enhances the absorption of calcium from the gut. The release of calcium from the bones is increased and the urinary excretion of calcium is decreased (Haram et al. 1993). It would be expected, then, that bone resorption would be higher among lactating women than in nonlactating women and that the rate of bone resorption would be related to both dietary calcium and levels of PTH. Biochemical markers of bone turnover, such as osteocalcin, bone-specific alkaline phosphatase, and $\mathrm{N}$-telopeptide are increased during lactation (Sowers et al. 1995). However, animal studies indicate that bone loss during lactation is independent of PTH and vitamin D levels (Brommage \& DeLuca, 1985; Garner et al. 1990) and that it will occur during lactation even in the absence of parathyroid tissue (Hodnett et al. 1992). In humans, bone loss has been reported to occur independently of calcium intake, and studies of calciotrophic hormones such as PTH have yielded inconsistent results (Sowers et al. 1993). Recently, a 'humoral hypercalcemia factor' has been identified that mobilizes calcium for breast milk. This factor, PTH-related peptide, has been associated with breast feeding status, elevated prolactin levels, lower serum oestradiol levels, and bone mineral density change in humans (Sowers et al. 1996).

Bone mass is also affected by circulating gonadotrophins. It is well documented that bone loss can be significant among amenorrhoeic women. Low levels of serum oestrogens are associated with increased mobilization of bone and higher levels have been reported to be protective against bone loss (Mehta, 1993). Progesterone-only oral contraceptives have been reported to reduce the rate of bone loss among lactating women (Caird et al. 1994). The biological basis for these findings has been supported by the discovery of oestrogen and progesterone receptors in the trabecular bone (Frenay et al. 1991).

Evidence suggests that bone loss during lactation is usually reversed after weaning (Kalkwarf \& Specker, 1995). Infant feeding practices are known to affect the return of menstrual activity. When menstrual cycles resume, oestrogen levels rise and facilitate bone remineralization (Sowers et al. 1995). Elevated levels of PTH and $1,25(\mathrm{OH})_{2}$ vitamin D have been reported in the postweaning period (Specker et al. 1991). However, the degree to which these hormones may interact with circulating oestrogens and other factors is unknown.

The above metabolic changes are consistent with numerous reports that bone mineralization decreases during lactation (Chan et al. 1982; Wardlaw \& Pike, 1986; Chan et al. 1987; Hayslip et al. 1989; Tylavsky et al. 1989; Kent et al. 1990; Sowers et al. 1993; Cross et al. 1995; Kalkwarf \& Specker, 1995; Sowers et al. 1995) and that compensatory remineralization occurs after weaning (Lambke et al. 1977; Cann, 1989; Kent et al. 1990; Sowers et al. 1993; Cross et al. 1995; Kalkwarf \& Specker, 1995; Sowers et al. 1995). Although complete recovery is expected to take place after weaning, it is possible that low calcium intakes or repeated pregnancies limit bone remineralization and increase risk of osteoporosis and fractures in later life. However, the evidence suggests that the pattern of loss followed by recovery is not affected by calcium intake (Cross et al. 1995b) even among populations with low calcium intakes (Prentice et al. 1995). In a study of Gambian women randomly assigned to receive a calcium supplement or a placebo for up to 78 weeks of lactation, there was no effect of the supplement on bone mineral density even though the 
calcium intake of the supplemented group was increased by more than $700 \mathrm{mg} / \mathrm{d}$ (Prentice et al. 1995).

Repeated pregnancy was not found to result in lower bone mineralization in a study of US women. Sowers et al. (1995) evaluated whether pregnancy after an extended period of lactation affected maternal bone mass. In this longitudinal study, bone mineral density was compared between a group of women who had a subsequent pregnancy within 18 months of initiating lactation (cases) and those who had not (controls). There was no difference between groups in bone mineral density which was assessed at 3 weeks after delivery of the second child among the cases and at 9-10 months post partum among the controls. The authors speculated that recovery of bone mass between pregnancies was related to circulating oestrogen levels. Women with closely spaced pregnancies may have resumed ovulation earlier and therefore had higher oestrogen levels than the comparison group-levels which would have resulted in recovery of bone mass between the periods of lactation.

Several studies have reported a long term decrease in bone density associated with lactation (Atkinson \& West, 1970; Goldsmith \& Johnston, 1975; Wasnich et al. 1983; Lissner et al. 1991), while others have shown an increase (Lamke et al. 1977; Aloia et al. 1983; Hreshchyshyn et al. 1988; Stevenson et al. 1989; Feldblum et al. 1992; Berning et al. 1993). Many studies have shown no long term effect of lactation on maternal bone density (KritzSilverstein et al. 1992; Sowers et al. 1992; Bauer et al. 1993; Fox et al. 1993; Shaw, 1993). Interpretation of these studies is limited by the many factors that make the association between lactation and bone mass a complicated one. For example, the site selected to assess bone mass may affect the results. Trabecular bone is more metabolically active and is more labile under calcium homeostatic stress than is cortical bone (Kent et al. 1990). Furthermore, the duration of anovulation differs among lactating women and varies with infant feeding practices. As previously explained, the duration of anovulation has a significant effect on the rate of postpartum bone loss.

In a case-control study of women with osteoporosis $v$. age matched controls, Aloia et al. (1985) found that osteoporotic women had breast fed less than controls (16 v. $35 \%$ respectively). More recently, Shaw (1993) reported that breast feeding history was negatively associated with risk of osteoporosis in bivariate analyses, but was no longer significant in multiple regressions controlling for menopausal status, age, body mass index, and dietary factors. Breast feeding was categorized only as 'ever' or 'never' in that study.

Results from studies examining the role of reproductive factors in the risk of fractures among postmenopausal women have been mixed. Alderman et al. (1986) and Tuppurainen and coworkers (1995) found no association between breast feeding history and subsequent fractures. However, Kreiger et al. (1982) and Cumming \& Klineberg (1993) found a protective effect of breast feeding.

To summarize, it is apparent that bone loss is obligatory during lactation and that physiological mechanisms are in place to ensure that sufficient amounts of calcium are delivered to the mammary gland. These mechanisms are independent of calcium intake and are linked with maternal ovulatory status. Recovery of bone mass occurs after weaning and may be influenced by feeding practices which affect both calcium homeostasis and the duration of anovulation. The majority of the studies listed here included only Caucasian women from relatively affluent populations. Further research needs to be conducted among more diverse populations, especially women who may be at greater risk of calcium depletion such as teenagers, who require calcium for their own bone growth, and women with many pregnancies followed by extended lactation. 


\section{Conclusions}

Lactation results in a number of physiological changes that affect maternal health, some of which may confer both short and long term advantages for breast feeding mothers. Breast feeding in the early postpartum period promotes a more rapid return of the uterus to its prepregnant state through the actions of oxytocin. Breast feeding may also lead to a more rapid return to prepregnancy weight. Among studies that defined breast feeding using a duration of at least 3 months or had good data on duration and intensity of lactation, the majority show a significant association between lactation and weight loss.

Physiological adaptations to lactation also affect glucose and lipid metabolism. The long term effects of these adaptations are unknown but may have implications for preventing subsequent development of diabetes and heart disease.

It is well documented that lactation delays the return of ovulation and significantly reduces fertility during the period of lactational amenorrhoea. This process is tightly linked with the frequency and timing of infant suckling and may therefore be affected by infant feeding practices such as scheduled feedings and the timing of introduction of complementary foods.

The association between lactation and subsequent risk of cancer is complex and may be related to several physiological changes, not just the reduction of circulating gonadotrophins and suppression of ovulation. For example, risk of breast cancer may also be affected by structural changes in the mammary gland and lowered exposure to carcinogenic compounds as a result of lactation and milk removal. While the evidence from epidemiologic studies is mixed, several large studies have shown that extended lactation is associated with reduced risk for premenopausal breast, ovarian, and endometrial cancers. Well controlled studies are needed that include detailed information regarding infant feeding practices in addition to the total duration of breast feeding.

Although bone mineralization declines during lactation, repletion takes place after weaning. As a result, breast feeding does not appear to cause long term depletion of bone nor does it increase risk of osteoporosis. Further studies are needed to identify mechanisms for the apparent obligatory losses of bone mass during lactation and to examine how maternal diet, high parity, and infant feeding practices may affect this process.

Only in the last few years have researchers moved beyond the classification of breast feeding as 'ever' or 'never' in epidemiological studies. While well designed studies which include assessments of infant feeding practices are highly complex and expensive to conduct, they are vitally needed. Without such studies, we will be unable to further our understanding of the long term effects of lactation on maternal health. There is considerable evidence to suggest that there are significant health advantages for mothers who breast feed their infants. Unlike some risk factors for cancer and other illnesses, breast feeding is a factor which can be changed. However, it may not be enough to counsel women merely to 'breast feed' their infants if patterns of infant feeding (such as the exclusivity and duration of breast feeding) play an important role. Therefore, a clearer understanding of the underlying mechanisms is necessary. Future infant feeding recommendations should reflect careful consideration of how such practices affect both infant and maternal health.

\section{References}

Adair, L. S. \& Popkin, B. M. (1992). Prolonged lactation contributes to depletion of matemal energy reserves in Filipino women. Journal of Nutrition 122, 1643-1655.

Adami, H. O., Bergstrom, R., Lund, E. \& Meirik, O. (1990). Absence of association between reproductive variables and the risk of breast cancer in young women in Sweden and Norway. British Jourmal of Cancer 62, 122-126. 
Alderman, B. W., Weiss, N. S., Daling, J. R., Ure, C. L. \& Ballard, J. H. (1986). Reproductive history and postmenopausal risk of hip and forearm fracture. American Journal of Epidemiology 124, 262-267.

Aloia, J. F., Cohn, S. H., Vaswani, A., Yeh, J. K., Yuen, K. \& Ellis, K. (1985). Risk factors for postmenopausal osteoporosis. American Journal of Medicine 78, 95-100.

Aloia, J. F., Vaswani, A. N., Yeh, J. K., Ross, P., Ellis, K. \& Cohn, S. H. (1983). Determinants of bone mass in postmenopausal women. Archives of Internal Medicine 143, 1700-1704.

Atkinson, P. J. \& West, R. R. (1970). Loss of skeletal calcium in lactating women. Joumal of Obstetrics and Gynaecology of the British Commonwealth 77, 555-560.

Baird, D. T., McNeilly, A. S., Sawers, R. S. \& Sharpe, R. M. (1979). Failure of estrogen-induced discharge of luteinizing hormone in lactating women. Joumal of Clinical Endocrinology and Metabolism 49, 500-506.

Bauchner, H., Leventhal, J. M. \& Shapiro, E. D. (1986). Studies of breastfeeding and infections: How good is the evidence? Journal of the American Medical Association 256, 887-892.

Bauer, D. C., Browner, W. S., Cauley, J. A., Orwoll, E. S., Scott, J. C., Black, D. M., Tao, J. L. \& Cummings, S. R. (1993). Factors associated with appendicular bone mass in older women. Annals of Internal Medicine 118, 657-665.

Berning, B., van Kuijk, C., Schutte, H. E., Kuiper, J. W., Drogendijk, A. C. \& Fauser, C. J. M. (1993). Determinants of lumbar bone mineral density in normal weight, non-smoking women soon after menopause. A study using clinical data and quantitative computed tomography. Bone and Mineral 21, 129-139.

Bjorkelund, C., Lissner, L., Andersson, S., Lapidus, L. \& Bengtsson, C. (1996). Reproductive history in relation to relative weight and fat distribution. Intemational Joumal of Obesity and Related Metabolic Disorders 20, 213-219.

Boardley, D. J., Sargent, R. G., Coker, A. L., Hussey, J. R. \& Sharpe, P. A. (1995). The relationship between diet, activity, and other factors, and postpartum weight change by race. Obstetrics and Gynecology 86, 834-838.

Brewer, M. M., Bates, M. R. \& Vannoy, L. P. (1989). Postpartum changes in maternal weight and body fat depots in lactating vs nonlactating women. American Joumal of Clinical Nutrition 49, 259-265.

Brinton, L. A., Berman, M. L., Mortel, R., Twiggs, L. B., Barrett, R. J., Wilbanks, G. D., Lannom, L. \& Hoover, R. N. (1992). Reproductive, menstrual, and medical risk factors for endometrial cancer: results from a case-control study. American Journal of Obstetrics and Gynecology 167, 1317-1325.

Brinton, L. A., Hoover, R. \& Fraumeni, J. F. (1983). Reproductive factors in the aetiology of breast cancer. British Joumal of Cancer, 47, 757-762.

Brommage, R. \& DeLuca, H. F. (1985). Regulation of bone mineral loss during lactation. American Journal of Physiology 248, E182-E187.

Byers, T., Graham, S., Rzepka, T. \& Marshall, J. (1985). Lactation and breast cancer. Evidence for a negative association in premonenopausal women. American Joumal of Epidemiology 121, 664-674.

Caird, L. E., Reid-Thomas, V., Hannan, W. J., Gow, S. \& Glasier, A. F. (1994). Oral progestogen-only contraception may protect against loss of bone mass in breast-feeding women. Clinical Endocrinology 41, 739-45.

Campbell, O. M. R. \& Gray, R. H. (1993). Characteristics and determinants of postpartum ovarian function in women in the United States. American Journal of Obstetrics and Gynecology 169, 55-60.

Cann, C. E. (1989). Pregnancy and lactation cause reversible trabecular bone loss in humans. Joumal of Bone and Mineral Research 4, S384.

Chan, G. M., McMurry, M., Westover, K., Engelbert-Fenton, K. \& Thomas, M. R. (1987). Effects of increased dietary calcium intake upon the calcium and bone mineral status of lactating adolescent and adult women. American Joumal of Clinical Nutrition 46, 319-323.

Chan, G. M., Slater, P., Nonie, R., Ronald, N., Roberts, C. C., Thomas, M. R., Folland, D. \& Jackson, R. (1982). Bone mineral status of lactating mothers of different ages. American Joumal of Obstetrics and Gynecology 144, $438-441$.

Chilvers, C. E. D. (Ed.) (1993). Breast feeding and risk of breast cancer in young women. British Medical Journal 307, 17-20.

Cohn, S. H., Abesamis, C., Yasumura, S., Aloia, J. F., Zanzi, I. \& Ellis, K. J. (1977). Comparative skeletal mass and radial bone mineral content in black and white women. Metabolism 26, 171-178.

Cramer, D. W., Hutchison, G. B., Welch, W. R., Scully, R. E. \& Ryan, K. J. (1983). Determinants of ovarian cancer risk. I. Reproductive experiences and family history. Journal of the National Cancer Institute 71, 711-716.

Cross, N. A., Hillman, L. S., Allen, S. H. \& Krause, G. F. (1995a). Changes in bone mineral density and markers of bone remodeling during lactation and postweaning in women consuming high amounts of calcium. Journal of Bone and Mineral Research 10, 1312-1320.

Cross, N. A., Hillman, L. S., Allen, S. H., Krause, G. F. \& Vieira, N. E. (1995b). Calcium homeostasis and bone metabolism during pregnancy, lactation, and postweaning: a longitudinal study. American Joumal of Clinical Nutrition 61, 514-523.

Cumming, R. G. \& Klineberg, R. J. (1993). Breastfeeding and other reproductive factors and the risk of hip fractures in elderly women. International Journal of Epidemiology 22, 684-691.

Daly, S. E. \& Hartmann, P. E. (1995). Infant demand and milk supply. Pan 2: The short-term control of milk synthesis in lactating women. Journal of Human Lactation 11, 27-37.

Dewey, K. G., Cohen, R. J., Landa Rivera, L., Canahuati, J. \& Brown, K. H. (1997). Effects of age at introduction of complementary foods to breastfed infants on duration of lactational amenornhea in Honduran women. American Joumal of Clinical Nutrition 65, 1403-1409.

Dewey, K. G., Heinig, M. J. \& Nommsen, L. A. (1993). Maternal weight-loss patterns during prolonged lactation. American Joumal of Clinical Nutrition 58, 162-166. 
Diaz, S., Cardenas, H., Brandeis, A., Miranda, P., Salvatierra, A. M. \& Croxatto, H. B. (1992). Relative contributions of anovulation and luteal phase defect to the reduced pregnancy rate of breastfeeding women. Ferility and Sterility 58, $498-503$.

Dugdale, A. E. \& Eaton-Evans, J. (1989). The effect of lactation and other factors on post-partum changes in body weight and triceps skinfold thickness. British Journal of Nutrition 61, 149-153.

Feldblum, P. J., Zhang, J., Rich, L. E., Fortney, J. A. \& Talmage, R. V. (1992). Lactation history and bone mineral density among perimenopausal women. Epidemiology 3, 527-531.

Fox, K. M., Magaziner, J., Sherwin, R., Scott, J. C., Plato, C. C., Nevitt, M. \& Cummings, S. (1993). Reproductive correlates of bone mass in elderly women. Journal of Bone and Mineral Research 8, 901-908.

Frenay, M., Milano, G., Formento, J. L., Franconal, M., Moll, J. L. \& Namer, M. (1991). Oestrogen and progesterone receptor status in bone biopsy specimens from patients with breast cancer. European Joumal of Cancer 27, $115-118$.

Garner, S. C., Boass, A. \& Toverud, S. U. (1990). Parathyroid hormone is not required for normal milk composition or secretion or lactation-associated bone loss in normocalcemic rats. Joumal of Bone and Mineral Research 5, 69-75.

Glasier, A. \& McNeilly, A. S. (1990). Physiology of lactation. In: Bailliere's Clinical Endocrinology and Metabolism: Endocrinology of Pregnancy. pp. 379-395 [S. Franks, editor]. London: Bailliere Tindall.

Goldsmith, N. F. \& Johnston, J. O. (1975). Bone mineral: effect of oral contraceptives, pregnancy, and lactation. Journal of Bone and Joint Surgery 57A, 657-668.

Greene, G. W., Smicklas-Wright, H., Scholl, T. O. \& Karp, R. J. (1988). Postpartum weight change. How much of the weight gained in pregnancy will be lost after delivery? Obstetrics and Gynecology 71, 701-707.

Gross, B. A. \& Eastman, C. J. (1985). Prolactin and the return of ovulation in breast-feeding women. Joumal of Biosocial Science 9 (Suppl), 25-42.

Gwinn, M. L., Lee, N. C., Rhodes, P. H., Layde, P. M. \& Rubin, G. L. (1990). Pregnancy, breastfeeding and oral contraceptives and the risk of epithelial ovarian cancer. Journal of Clinical Epidemiology 43, 559-568.

Haram, K., Thordarson, H. \& Hervig, T. (1993). Calcium homeostasis in pregnancy and lactation. Acta Obstetricia et Gynecologica Scandinavica 72, 509-513.

Hartge, P., Schiffman, M. H., Hoover, R., McGowan, L., Lesher, L. \& Norris, H. J. (1989). A case-control study of epithelial ovarian cancer. American Joumal of Obstetrics and Gynecology 161, 10-16.

Hayslip, C. C., Klein, T. A., Wray, H. L. \& Duncan, W. E. (1989). The effects of lactation on bone mineral content in healthy postpartum women. Obstetrics and Gynecology 73, 588-592.

Heinig, M. J. \& Dewey, K. G. (1996). Health advantages of breast feeding for infants: a critical review. Nutrition Research Reviews 9, 89-110.

Henderson, B. E., Ross, R. K., Pike, M. C. \& Casagrande, J. T. (1982). Endogenous hormones as a major factor in human cancer. Cancer Research 42, 3232-3239.

Hildreth, N. G., Kelsey, J. L., LiVolsi, V. A., Fisher, D. B., Holford, T. R., Mostow, E. D., Schwartz, P. E. \& White, C. (1981). An epidemiologic study of epithelial carcinoma of the ovary. American Journal of Epidemiology 114, 398-405.

Hodnett, D. W., DeLuca, H. F. \& Jorgensen, N. A. (1992). Bone mineral loss during lactation occurs in absence of parathyroid tissue. American Joumal of Physiology 262, E230-E233.

Howie, P. W. \& McNeilly, A. S. (1982). Effect of breast feeding patterns on human birth intervals. Joumal of Reproduction and Fertility 65, 545-557.

Howie, P. W., McNeilly, A. S., Houston, M. J., Cook, A. \& Boyle, H. (1981). Effect of supplementary food on suckling patterns and ovarian activity during lactation. British Medical Journal 283, 757-759.

Hreshchyshyn, M. M., Hopkins, A., Zylstra, S. \& Anbar, M. (1988). Associations of parity, breastfeeding, and birth control pills with lumbar spine and femoral neck bone densities. American Journal of Obstetrics and Gynecology 159, 318-322.

Ing, R., Ho, J. H. C. \& Petrakis, N. L. (1977). Unilateral suckling and breast cancer. Lancet ii, 656-657.

Institute of Medicine (1991). Nutrition during Lactation. Washington, D. C.: National Academy Press.

Janney, C. A., Zhang, D. \& Sowers, M. F. (1996). Lactation and Weight Retention. Washington, DC: Federation of American Societies for Experimental Biology.

Jen, K.-L. C., Juuhl, N. \& Lin, P. K. H. (1988). Repeated pregnancy without lactation. Effects on carcass composition and adipose tissue cellularity in rats. Journal of Nutrition 118, 93-98.

Jimenez, D. M., Pocovi, M., Ramon-Cajal, J., Romero, M. A., Martinez, H. \& Grande, F. (1988). Longitudinal study of plasma lipids and lipoprotein cholesterol in normal pregnancy and puerperium. Gynecological and Obstetric Investigation 25, 158-164.

John, E. M., Whittemore, A. S., Harris, R. \& Itnyre, J. (1993). Characteristics relating to ovarian cancer risk: collaborative analysis of seven United States case-control studies. Epithelial ovarian cancer in black women. Joumal of the National Cancer Institute 85, 142-147.

Josephy, P. D. (1996). The role of peroxidase-catalyzed activation of aromatic amines in breast cancer. Mutagenesis 11, 3-7.

Kalkwarf, H. J. \& Specker, B. L. (1995). Bone mineral loss during lactation and recovery after weaning. Obstetrics and Gynecology 86, 26-32.

Kallio, M. T., Siimes, M. A., Perheentupa, J., Salmenperä, L. \& Miettinen, T. A. (1989). Cholesterol and its precursors in human milk during prolonged exclusive breastfeeding. American Journal of Clinical Nutrition 50, 782-785. 
Kallio, M. J. T., Siimes, M. A., Perheentupa, J., Salmenperä, L. \& Miettinen, T. A. (1992). Serum cholesterol and lipoprotein concentrations in mothers during and after prolonged exclusive lactation. Metabolism 41, 1327-1330.

Kampert, J. B., Whittemore, A. S. \& Paffenbarger, R. S. (1988). Combined effect of childbearing, menstrual events, and body size on age-specific breast cancer risk. American Journal of Epidemiology 128, 962-979.

Katsouyanni, K., Lipworth, L., Trichopoulou, A., Samoli, E., Stuver, S. \& Trichopoulos, D. (1996). A case-control study of lactation and cancer of the breast. British Journal of Cancer 73, 814-818.

Kennedy, K. I. Rivera, R. \& McNeilly, A. S. (1989). Consensus statement on the use of breastfeeding as a family planning method. Contraception 39, 477-496.

Kent, G. N., Price, R. I., Gutteridge, D. H., Smith, M., Allen, J. R., Bhagat, C. I., Barnes, M. P., Hickling, C. J., Retallack, R. W., Wilson, S. G., Devlin, R. D., Davies, C. \& St. John, A. (1990). Human lactation: forearm trabecular bone loss, increased bone tumover, and renal conservation of calcium and inorganic phosphate with recovery of bone mass following weaning. Journal of Bone and Mineral Research 5, 361-369.

Keppel, K. G. \& Taffel, S. M. (1993). Pregnancy-related weight gain and retention: implications of the 1990 Institute of Medicine guidelines. American Joumal of Public Health 83, 1100-1103.

King, J. C., Halloran, B. P., Huq, N., Diamond, T. \& Buckendahl, P. E. (1992). Calcium metabolism during pregnancy and lactation. Mechanisms regulating Lactation and Infant Nutrient Utilization, vol. 15, pp. 129-146 [M. F. Picciano and B. Lonnerdal, editors]. New York: Wiley-Liss.

Kjos, S. L., Henry, O., Lee, R. M., Buchanan, T. A. \& Mishell, D. R. (1993). The effect of lactation on glucose and lipid metabolism in women with recent gestational diabetes. Obstetrics and Gynecology 82, 451-455.

Knopp, R. H., Bergelin, R. O., Wahl, P. W. \& Walden, C. E. (1985a). Effects of pregnancy, postpartum lactation and oral contraceptive use on the lipoprotein cholesterol/triglyceride ratio. Metabolism 34, 893-899.

Knopp, R. H., Bergelin, R. O., Wahl, P. W., Walden, C. E., Chapman, M. \& Irvine, S. (1982). Population based lipoprotein lipid reference values for pregnant women compared to nonpregnant women classified by sex hormone usage. American Journal of Obstetrics and Gynecology 143, 626-637.

Knopp, R. H., Walden, C. E., Wahl, P. W., Bergelin. R., Chapman, M., Irvine, S. \& Albers, J. J. (1985b). Effect of postpartum lactation on lipoprotein lipids and apoproteins. Joumal of Clinical Endocrinology and Metabolism 60, $542-547$.

Kramer, F. M., Stunkard, A. J., Marshall, K. A., McKinney, S. \& Liebschutz, J. (1993). Breastfeeding reduces maternal lower-body fat. Joumal of the American Dietetic Association 93, 429-433.

Kreiger, N., Kelsey, J. L., Holford, T. R. \& O'Connor, T. (1982). An epidemiologic study of hip fracture in postmenopausal women. American Joumal of Epidemiology 116, 141-148.

Kritz-Silverstein, D., Barrett-Connor, E. \& Hollenbach, K. A. (1992). Pregnancy and lactation as determinants of bone mineral density in postmenopausal women. American Journal of Epidemiology 136, 1052-1059.

Kuhns, J. G. \& Ackermann, D. M. (1995). Microscopic anatomy of the breast. In Cancer of the Breast, pp. 16-21 [W. L. Donnegan and J. S. Spratt, editors]. Philadelphia, PA: W. B. Saunders Co.

Kvale, G. \& Heuch, I. (1987). Lactation and cancer risk: is there a relation specific to breast cancer? Joumal of Epidemiology and Community Health 42, 30-37.

Laing, A. E., Demenais, F. M., Williams, R., Kissling, G., Chen, V. W. \& Bonney, G. E. (1993). Breast cancer risk factors in African-American women: the Howard University Tumor Registry experience. Journal of the National Medical Association 85, 931-939.

Lamke, B., Brundin, J. \& Moberg, P. (1977). Changes in bone mineral content during pregnancy and lactation. Acta Obstetricia et Gynecologica Scandinavica 56, 217-219.

Lawrence, R. A. (1994). Breastfeeding: a Guide for the Medical Profession, 4th edn. St. Louis, MO: Mosby.

Layde, P. M., Webster, L. A., Baughman, A. L., Wingo, P. A., Rubin, G. L. \& Ory, H. W. (1989). The independent associations of parity, age at first full term pregnancy, and duration of breastfeeding with the risk of breast cancer. Cancer and Steroid Hormone Study Group. Joumal of Clinical Epidemiology 42, 963-973.

Lenz, S., Kühl, C., Hornnes, P. J. \& Hagen, C. (1981). Influences of lactation on oral glucose tolerance in the puerperium. Acta Endocrinologica 98, 428-431.

Lissner, L., Bengtsson, C. \& Hansson, T. (1991). Bone mineral content in relation to lactation history in pre- and postmenopausal women. Calcified Tissue International 48, 319-325.

London, S. J., Colditz, G. A., Stampfer, M. J., Willett, W. C., Rosner, B. A., Corsano, K. \& Speizer, F. E. (1990). Lactation and risk of breast cancer in a cohort of United States women. American Journal of Epidemiology 132, $17-$ 26.

McNeilly, A. S., Tay, C. C. \& Glasier, A. (1994). Physiological mechanisms underlying lactational amenorrhea. Annals of the New York Academy of Sciences 709, 145-155.

McTiernan, A. \& Thomas, D. B. (1986). Evidence for a protective effect of lactation on risk of breast cancer in young women. Results from a case-control study. American Joumal of Epidemiology 124, 353-358.

Manning-Dalton, C. \& Allen, L. H. (1983). The effects of lactation on energy and protein consumption, postpartum weight change and body composition of well nourished North American women. Nutrition Research 3, $293-308$.

Mansfield, C. M. (1993). A review of the etiology of breast cancer. Journal of the National Medical Association 85 , 217-221.

Mehta, S. (1993). Bone loss, contraception and lactation. Acta Obstetricia et Gynecologica Scandinavica 72, $148-156$.

Melton, L. J. \& Riggs, B. L. (1983). Epidemiology of age related fractures. In The Osteoporotic Syndrome: Detection, Prevention, and Treatment, pp. 45-72 [L. V. Avioli, editor]. New York: Grune and Stratton. 
Mepham, T. B. (1987). Physiology of Lactation. Milton Keynes: Open University Press.

Michels, K. B., Willett, W. C., Rosner, B. A., Manson. J. E., Hunter, D. J., Colditz, G. A., Hankinson, S. E. \& Speizer, F. E. (1996). Prospective assessment of breastfeeding and breast cancer incidence among 89887 women. Lancet 347 , 431-436.

Moore, B. J., Gerardo-Gettens, T., Horwitz, B. A. \& Stern, J. S. (1986). Hyperprolactinemia stimulates food intake in the female rat. Brain Research Bulletin 17, 563-569.

Negri, E., Braga, C., La Vecchia, C., Levi, F., Talamini, R. \& Franceschi, S. (1996). Lactation and the risk of breast cancer in an Italian population. International Joumal of Cancer 67, 161-164.

Neville, M. C. \& Neifert, M. R., Eds. (1983). Lactation: Physiology, Nutrition, and Breast-feeding. New York: Plenum Press.

Newcomb, P. A., Storer, B. E., Longnecker, M. P., Mittendorf, R., Greenberg, E. R., Clapp, R. W., Burke, K. P., Willett, W. C. \& MacMahon, B. (1994). Lactation and a reduced risk of premenopausal breast cancer. New England Journal of Medicine 330, 81-87.

Ohlin, A. \& Rössner, S. (1990). Maternal body weight development after pregnancy. Intemational Journal of Obesity 14, 159-173.

Parker, J. D. (1993). Postpartum weight change. Clinical Obstetrics and Gynecology 37, 528-537.

Perez, A. (1981). Natural family planning: postpartum period. International Joumal of Fertility 26, $219-221$.

Perez, A., Vela, P., Masnick, G. S. \& Potter, R. G. (1972). First ovulation after childbirth: the effect of breastfeeding. American Joumal of Obstetrics and Gynecology 114, 1041-1047.

Petrakis, N. L., Wrensch, M. R., Ernster, V. L., Miike, R., Murai, J., Simberg, N. \& Siiteri, P. K. (1987). Influence of pregnancy and lactation on serum and breast fluid estrogen levels: implications for breast cancer risk. Intemational Journal of Cancer 40, 587-591.

Potter, S., Hannum, S., McFarlin, B., Essex-Sorlie, D., Campbell, E. \& Trupin, S. (1991). Does infant feeding method influence maternal postpartum weight loss? Joumal of the American Dietetic Association 91, 441-446.

Prentice, A., Jarjou, L. M. A., Cole, T. J., Stirling, D. M., Dibba, B. \& Fairweather-Tait, S. (1995). Calcium requirements of lactating Gambian mothers: effects of a calcium supplement on breast-milk calcium concentration, maternal bone mineral content, and urinary calcium excretion. American Joumal of Clinical Nutrition 62, 58-67.

Riordan, J. (1993). Anatomy and psychophysiology of lactation. In Breastfeeding and Human Lactation, pp. 81-104 [J. Riordan and K. G. Auerbach, editors]. Boston, MA: Jones and Bartlett.

Risch, H. A., Weiss, N. S., Lyon, J. L., Daling, J. R. \& Liff, J. M. (1983). Events of reproductive life and the incidence of epithelial ovarian cancer. American Journal of Epidemiology 117, 128-139.

Romieu, I., Hemandez-Avila, M., Lazcano, E., Lopez, L. \& Romero-Jaime, R. (1996). Breast cancer and lactation history in Mexican women. American Journal of Epidemiology 143, 543-552.

Rosenblatt, K. A. \& Thomas, D. B. (1995). Prolonged lactation and endometrial cancer. WHO Collaborative Study of Neoplasia and Steroid Contraceptives. International Joumal of Epidemiology 24, 499-503.

Rosenblatt, K. A., Thomas, D. B., Berry, G., MacLennan, R., Shearman, R., Jelikovsky, T., Booth, J. C., Molina, R., Martinez, L. \& Sales, O. (1993). Lactation and the risk of epithelial ovarian cancer. The WHO Collaborative Study of Neoplasia and Steroid Contraceptives. International Journal of Epidemiology 22, 192-197.

Rosero-Bixby, L., Oberle, M. W. \& Lee, N. C. (1987). Reproductive history and breast cancer in a population of high fertility, Costa Rica, 1984-85. International Joumal of Cancer 40, 747-754.

Rush, D., Lumey, L. H., Ravelli, A. C. J. \& Myers, B. (1996). The indirect association of lactation with subsequent perimenopausal body weight. European Journal of Clinical Nutrition 50, 12-16.

Russo, J. \& Russo, I. H. (1995). The etiopathogenesis of breast cancer prevention. Cancer Letters 90, 81-89.

Russo, J., Tay, L. K. \& Russo, 1. H. (1982). Differentiation of the mammary gland and susceptibility to carcinogenesis, a review. Breast Cancer Research and Treatment 2, 5-73.

Schauberger, C. W., Rooney, B. L. \& Brimer, L. M. (1992). Factors that influence weight loss in the puerperium. Obstetrics and Gynecology 79, 424-429.

Scholl, T. O., Hediger, M. L., Schall, J. I., Ances, I. G. \& Smith, W. K. (1995). Gestational weight gain, pregnancy outcome, and postpartum weight retention. Obstetrics and Gynecology 86, 423-427.

Shaw, C.-K. (1993). An epidemiologic study of osteoporosis in Taiwan. Annals of Epidemiology 3, $264-271$.

Shi, Y. E., Liv, Y. L. E., Lippman, M. E. \& Dickson, R. B. (1994). Progestins and antiprogestins in mammary tumour growth and metastasis. Human Reproduction 9 (Suppl. 1) 162-173.

Short, R. V., Lewis, P. R., Renfree, M. B. \& Shaw, C. (1991). Contraceptive effects of extended lactational amenorrhoea. Beyond the Bellagio Consensus. Lancet 337, 715-717

Siskind, V., Schofield, F., Rice, D. \& Bain, C. (1989). Breast cancer and breastfeeding. Results from an Australian casecontrol study. American Joumal of Epidemiology 130, 229-236.

Sowers, M. R., Clark, M. K., Hollis, B., Wallace, R. B. \& Jannausch. M. (1992). Radial bone mineral density in pre- and perimenopausal women: a prospective study of rates and risk factors for loss. Journal of Bone and Mineral Research 7, 647-657.

Sowers, M., Corton, G., Shapiro, B., Jannausch, M. L., Crutchfield, M., Smith, M. L., Randolph, J. F. \& Hollis, B. (1993). Changes in bone density with lactation. Journal of the American Medical Association 269, 3130-3135.

Sowers, M., Eyre, D., Hollis, B. W., Randolph, J. F., Shapiro, B., Jannausch, M. L. \& Crutchfield, M. (1995). Biochemical markers of bone tumover in lactating and nonlactating postpartum women. Journal of Clinical Endocrinology and Metabolism 80, 2210-2216. 
Sowers, M. F., Hollis, B. W., Shapiro, B., Randolph, J., Janney, C. A., Zhang, D., Schork, A., Crutchfield, M., Stanczyk, F. \& Russell-Aulet, M. (1996). Elevated parathyroid hormone-related peptide associated with lactation and bone density loss. Joumal of the American Medical Association 276, 549-554.

Specker, B. L., Tsang, R. C. \& Ho, M. L. (1991). Changes in calcium homeostasis over the first year postpartum: effect of lactation and weaning. Obstetrics and Gynecology 78, 56-62.

Spicer, D. V. \& Pike, M. C. (1994). Steroids and breast cancer prevention. Journal of the National Cancer Institute Monographs 16, 139-147.

Stevenson, J. C., Lees, B., Davenpor, M., Cust, M. P. \& Ganger, K. F. (1989). Determinants of bone density in normal women: Risk factors for future osteoporosis? British Medical Journal 298, 924-928.

Tao, S.-C., Yu, M. C., Ross, R. K. \& Xiu, K.-W. (1988). Risk factors for breast cancer in Chinese women of Beijing. International Jourmal of Cancer 42, 495-498.

Thomas, D. B. \& Noonan, E. A. (1993). Breast cancer and prolonged lactation. The WHO Collaborative Study of Neoplasia and Steroid Contraceptives. International Journal of Epidemiology 22, 619-626.

Tuppurainen, M., Kroger, H., Saarikoski, S., Honkanen, R. \& Alhava, E. (1995). The effect of gynecological risk factors on lumbar and femoral bone mineral density in peri- and postmenopausal women. Maturitas 21, $137-145$.

Tylavsky, F. A., Curtis, R. C., Anderson, J. J. B. \& Metz, J. A. (1989). Changes in radial and vertebral bone mass due to pregnancy and lactations in humans. Journal of Bone and Mineral Research 4, S414.

Voigt, L. F. \& Weiss, N. S. (1989). Epidemiology of endometrial cancer. Cancer Treatment and Research 49, 1-21.

Wang, D. Y., de Stavola, B. L., Bulbrook, R. D., Allen, D. S., Kwa, H. G., Fentiman, I. S., Hayward, J. L. \& Millis, R. R. (1992). Relationship of blood prolactin levels and the risk of subsequent breast cancer. International Journal of Epidemiology 21, 214-221.

Wang, I. Y. \& Fraser, I. S. (1994). Reproductive function and contraception in the postpartum period. Obstetrical and Gynecological Survey 49, 56-63.

Wardlaw, G. M. \& Pike, A. M. (1986). The effect of lactation on peak adult shaft and ultra-distal forearm bone mass in women. American Joumal of Clinical Nutrition 44, 283-286.

Wasnich, R., Yano, K. \& Vogel, J. (1983). Postmenopausal bone loss at multiple skeletal sites: relationship to estrogen use. Journal of Chronic Diseases 36, 781-790.

West, R. O. (1966). Epidemiologic study of malignancies of the ovaries. Cancer 19, 1001-1007.

Whittemore, A. S. (1994). Characteristics relating to ovarian cancer risk: implications for prevention and detection. Gynecologic Oncology 55, S15-19.

Whittemore, A. S., Harris, R., Inyre, J. \& Group, C. O. C. (1992). Characteristics relating to ovarian cancer risk: collaborative analysis of 12 US case-control studies. II. Invasive epithelial ovarian cancers in white women. American Journal of Epidemiology 136, 1184-1203.

Wilde, C. J., Addey, C. V. P., Casey, M. J., Batchford, D. R. \& Peaker, M. (1988). Feedback inhibition of milk secretion: the effect of a fraction of goat milk on milk yield and composition. Quarterly Journal of Experimental Physiology 73, 391-397.

Wu, A. H., Ziegler, R. G., Pike, M. C., Nomura, A. M. Y., West, D. W., Kolonel, L. N., Horn-Ross, P. L., Rosenthal, J. F. \& Hoover, R. N. (1996). Menstrual and reproductive factors and risk of breast cancer in Asian-Americans. British Journal of Cancer 73, 680-686.

Wynder, E. L., Dodo, H. \& Barber, H. R. K. (1969). Epidemiology of cancer of the ovary. Cancer 23, 352-370.

Yang, C. P., Weiss, N. S., Band, P. R., Gallagher, R. P., White, E. \& Daling, J. R. (1993). History of lactation and breast cancer risk. American Journal of Epidemiology 138, 1050-1056.

Yano, K., Wasnich, R. D., Vogel, J. M. \& Heilbrun, L. K. (1984). Bone mineral measurements among middle aged and elderly Japanese residents in Hawaii. American Joumal of Epidemiology 119, 751-764.

Yoo, K. Y., Tajima, K., Kuroishi, T., Hirose, K., Yoshida, M., Miura, S. \& Murai, H. (1992). Independent protective effect of lactation against breast cancer: A case-control study in Japan. American Journal of Epidemiology 135, 726-733.

Yuan, J. M., Yu, M. C., Ross, R. K., Gao, Y. T. \& Henderson, B. E. (1988). Risk factors for breast cancer in Chinese women in Shanghai. Cancer Research 48, 1949-1953. 